\title{
Somatostatin Inhibits the Production of Interferon- $\gamma$ by Intestinal Epithelial Cells During Intestinal Ischemia-Reperfusion in Macaques
}

\author{
Ling Liu $\cdot$ Qinghua Tan $\cdot$ Bin Hu $\cdot$ Hao Wu \\ Chunhui Wang $\cdot$ Chengwei Tang
}

Received: 13 January 2014/ Accepted: 17 April 2014/Published online: 6 May 2014

(c) The Author(s) 2014. This article is published with open access at Springerlink.com

\begin{abstract}
Background Our previous study found that somatostatin (SST) inhibited the intestinal inflammatory injury in a macaque model of intestinal ischemia-reperfusion (IIR); however, the underlying mechanism was unclear.

Aims The present study was aimed to investigate the effects of SST on IFN- $\gamma$ and the systemic inflammatory response after IIR.

Methods Fifteen macaques were randomly divided into controls, IIR and SST+ IIR groups. ELISA was performed to measure IFN- $\gamma$ in ileum tissues, ileac epithelial cells (IECs) and ileal lymphocytes, as well as the systemic levels of IL- 6 , IL- $1 \beta$, TNF- $\alpha$ and IFN- $\gamma$ in the peripheral circulation and the portal vein. HE staining was performed to evaluate morphological changes in vital organs. Immunohistochemistry was performed to identify the distribution of IFN- $\gamma, \mathrm{CD} 4, \mathrm{CD} 8$ and CD57 in the ileum.

Results After IIR, IFN- $\gamma$ level was significantly increased in the IECs. IL-6, IL-1 $\beta$ and TNF- $\alpha$ were significantly increased in both the portal vein and the peripheral circulation; in contrast, IFN- $\gamma$ level was increased in the portal vein alone. Prophylactic SST reversed the change in IFN- $\gamma$ in the IECs and portal vein. SST led to an alleviation of the pathological changes in systemic vital organs. The distribution of $\mathrm{CD} 4^{+}, \mathrm{CD} 57^{+}$and $\mathrm{CD} 8^{+}$cells was not positively correlated with the secretion of IFN- $\gamma$.
\end{abstract}

L. Liu $\cdot$ Q. Tan $\cdot$ B. Hu $\cdot$ H. Wu $\cdot$ C. Wang $\cdot$ C. Tang $(\square)$ Department of Gastroenterology, West China Hospital, Sichuan University, Guoxue Lane 37\#, Chengdu 610041, People's Republic of China

e-mail: shcqcdmed@163.com
Conclusion IECs are the main source of IFN- $\gamma$ production after IIR. SST may indirectly lead to mast cell deactivation through the inhibition of IFN- $\gamma$ production by IECs. Pretreatment with SST may be beneficial for preventing a massive systemic inflammatory response in vital organs after IIR.

Keywords Somatostatin - Intestinal ischemiareperfusion · Interferon- $\gamma \cdot$ Macaques

\section{Introduction}

Intestinal ischemia-reperfusion (IIR) has been established as an important pathophysiological process in severe trauma, shock, severe acute pancreatitis, infection, organ transplantation and other inflammatory-related conditions [1]. Clinical and experimental studies performed during the past two decades have identified the gut as the "motor" of multiple organ dysfunction syndromes (MODS) in these critical conditions [2-4]. This is a highly active area of research as therapeutic approaches targeting the mechanisms to prevent and cure MODS would be of great value. A common theme of all these studies is that some element derived from the gut, such as from the intestinal epithelium, the mucosal immune system or commensal bacteria, contributes to critical illnesses [4]. However, as basic and clinic research has evolved, the mechanism by which the gastrointestinal tract drives systemic inflammation remains unclear.

Intestinal mucosal mast cells (IMMCs) are considered as one of the key initiators of the development of inflammation due to their participation in acute vasodilation, chemokine production, leukocyte trafficking, proinflammatory cytokine signaling, the degradation of the extracellular matrix, and immunomodulatory and counterinflammatory 
signaling [5-8] Preferentially, these cells are located in the perineuronal area, suggesting a potential interaction between mast cells and neuropeptides within the intestinal wall [6]. Somatostatin (SST), a multifunctional neuropeptide, is widely distributed throughout the central nervous system and peripheral tissues. Because of its wide distribution in the gastrointestinal tract and its wide variety of biological functions, the tetradecapeptide SST in the gut has attracted much attention. Our data and previous reports by other researchers have led us to conclude that SST inhibits the activation and degranulation of IMMC in vitro, decreases microvascular permeability and edema formation in the gut and leads to the alleviation of vital organ dysfunction in a rat model $[9,10]$. Furthermore, for greater relevance to human anatomy, physiology, biochemical metabolism and pathophysiology of diseases, we used an IIR macaque model to confirm that SST functions to prevent massive inflammatory injury in the intestinal mucosa [11]. The physiological functions of SST are initiated by its interaction with specific membrane-bound, high-affinity SST receptor (SSTR) on the surface of responsive cells. Interestingly, although we found SSTR-1 expression on the IMMCs of rats in a previous study [9], SSTR is not expressed on the activated IMMCs of macaques. There are insufficient data to interpret how SST modulates the function of mast cells after IIR in macaques.

IFN- $\gamma$, a regulatory cytokine that is critical for innate and adaptive immunity, has been shown to be predominantly synthesized and released by $\mathrm{CD}^{+} \mathrm{Th} 1, \mathrm{CD} 8^{+}$ cytotoxic $\mathrm{T}$ lymphocytes and natural killer cells [12]. Increasing evidence indicates that IFN- $\gamma$ exerts pleiotropic inflammatory effects through a specific receptor, leading to intestinal inflammation [13, 14]. Previous studies have shown that IFN- $\gamma$ is a negative regulator of mast cell functions, including adhesion, degranulation and cytokine release [15-17]. Research has also shown that IFN- $\gamma$ can up-regulate the function of the FceRI signal on mast cells through IFN- $\gamma$ receptors $[18,19]$. FceRI is an important signaling receptor in the activation process of intestinal mucosal mast cells. The consequence of FceRI activation is that the intestinal mucosal mast cells degranulate and release histamine, IL-6, IL-13, IL-33 and other inflammatory mediators $[18,19]$. Although the role of IFN $-\gamma$ in regulating mast cells is complex, these data confirm that the functional responses of mast cells could be directly regulated by IFN $-\gamma$. Therefore, we were intrigued by the idea that the indirect regulation of SST on mast cells might be caused by a direct effect of SST on IFN- $\gamma$.

This study was to examine the effects of SST on IFN- $\gamma$ and the systemic inflammatory response during MODS, thus elucidating the mechanism of SST in IMMCs. To provide greater clinical relevance, a macaque IIR model was used in this study.

\section{Materials and Methods}

\section{Experimental Animals}

Healthy adult rhesus macaques (4-7 years, body weight $6.9 \pm 1.7 \mathrm{~kg}$, male/female $=9 / 6$ ) were obtained from the Animal Center of Sichuan University. All the macaques were maintained in the facility after a quarantine inspection. The experiments in this study were performed in accordance with the guidelines of the Sichuan University Institutional Animal Care and Use Committee. All the animals were housed in an environment with a temperature of $20-22{ }^{\circ} \mathrm{C}$ with 12 -h light/ dark cycles. The animals were fasted for $12 \mathrm{~h}$, and drinking water was withdrawn $2 \mathrm{~h}$ before the experiment began.

\section{IIR Surgical Procedures in Macaques}

The animals were anesthetized with xylazine $(0.2 \mathrm{ml} / \mathrm{kg}$, i.m.) and maintained with diazepam $(0.1 \mathrm{ml} / \mathrm{kg}$, i.v. $)$ and carbrital (30 mg/kg, i.v.) as needed. A catheter was placed in a peripheral vein to infuse $0.9 \%$ saline and $20 \mathrm{~g}$ glucose $(0.1-0.2 \mathrm{ml} / \mathrm{kg} / \mathrm{min}$, i.v. gtt) for $24 \mathrm{~h}$. A midline laparotomy of $5 \mathrm{~cm}$ in length was performed. Then, the superior mesenteric artery (SMA) was isolated and occluded with a microsurgical clip. After occlusion for $1 \mathrm{~h}$, the clip was removed, and intestinal perfusion was reestablished. The animals were not provided any special volume resuscitation during or after the SMA occlusion, and the infusion of saline and glucose was maintained at the same speed as described above. Venous blood samples were collected again. The animals were killed $24 \mathrm{~h}$ after IIR via removal of the vital organs under anesthesia overdose.

\section{Experimental Grouping}

Fifteen macaques were randomly divided into three groups, with five animals (male/female $=3 / 2$ ) in each group. In the control group, the animals underwent a sham operation with the same treatment described above, except that the IIR procedure was not performed. In the IIR group, the animals underwent the IIR procedure. In the SST+IIR group, SST-14 (Serono Singapore Pte Ltd, Singapore) was administered to the animals intravenously via a syringe pump at a dosage of $5 \mu \mathrm{g} / \mathrm{kg} / \mathrm{h}$ from $5 \mathrm{~min}$ before SMA occlusion until the end of the experiment. The SST dosage $(5 \mu \mathrm{g} / \mathrm{kg} / \mathrm{h})$ of SST was based on the recommendation of $250 \mu \mathrm{g} / \mathrm{h}$ for human beings [20]. The other treatments for this group were the same as those for the IIR group.

\section{Morphological Study of Macaque Vital Organs}

Specimens were removed from the colon, liver and lung of each animal and were fixed with $10 \%$ formaldehyde. The 
histologic sections were evaluated in a blinded fashion. For the semiquantitative evaluation of inflammatory lesions in the vital organs, ten arbitrary microscopic fields were viewed in each sample. The scoring system was based on the area of the inflammatory lesion:,$+<1 / 3$ total area; ,$++ 1 / 3-2 / 3$ total area; and,$+++>2 / 3$ total area. [11] Disease score in one sample was calculated by the summary of the total score of 10 fields $(+, 1 ;++, 2 ;+++, 3)$.

Isolation of Intestinal Mucosa Epithelial Cells (IECs) and Lamina Propria Lymphocytes (LPLs)

Intestinal epithelial cells (IECs) and lamina propria lymphocytes (LPLs) were isolated following a previously described method [21, 22]. Briefly, the dissected terminal parts of the ileum were immediately placed in cold Hanks' fluid ( $\mathrm{pH}$ 7.4) and treated with $1 \mathrm{mM}$ DTT (Invitrogen, CA, USA) for $15 \mathrm{~min}$ to remove mucus. Then, the samples were cut into small pieces and placed into $20 \mathrm{ml}$ EDTA (Invitrogen, CA, USA) and $10 \mathrm{mM}$ D-Hanks' fluid (pH 7.4). The sample was shaken for $10-20 \mathrm{~min}$ at $37^{\circ} \mathrm{C}$. After the sediment from the tissue samples had settled, the supernatant was collected, filtered and centrifuged three times at $1,500 \mathrm{rpm}$ at $4{ }^{\circ} \mathrm{C}$ for $5 \mathrm{~min}$. The supernatant was discarded, and the sediment was gently resuspended in cold Hanks' fluid. Using this procedure, more than $95 \%$ of the cells were identified as mucosal epithelial cells, and their identities were confirmed by alkaline phosphatase rapid staining. The positive staining of intestinal epithelial cells was indicated by a gray-black cell membrane. The cells were shown to be alive by negative staining with $0.2 \%$ trypan blue.

To isolate LPLs, the remaining tissues were cut into 1-mm pieces and incubated 2-3 times in $5 \mathrm{ml}$ PBS containing $2.5 \mathrm{mg}$ collagenase D (Roche Applied Science, Indianapolis, IN), $2.5 \mathrm{mg}$ DNase (Sigma-Aldrich, St. Louis, MO) and $15 \mathrm{mg}$ dispase II (Roche Applied Science, Indianapolis, IN) at $37{ }^{\circ} \mathrm{C}$ for 20 min under slow rotation until the samples were digested into invisible small pieces. The supernatants were loaded on a Percoll gradient, and the LPL was collected at the interface between 35 and $70 \%$ Percoll (GE healthcare, Sweden) after centrifugation at $4{ }^{\circ} \mathrm{C}$ for $20 \mathrm{~min}$ at $1,000 \mathrm{~g}$. Single cells suspended at $2 \times 10^{6} \mathrm{ml}$ were cultured in RPMI 1,640 medium supplemented with $10 \%$ FCS and were stimulated with concanavalin A (5 mg/L) (Invitrogen, CA, USA) at $37{ }^{\circ} \mathrm{C}$ in a $5 \% \mathrm{CO} 2$ incubator. After incubation for $24 \mathrm{~h}$, the supernatants were collected and stored at $-70{ }^{\circ} \mathrm{C}$.

\section{Effects of SST on IECs In Vitro}

Isolated IECs were incubated in DMEM medium (10\% bovine serum, $100 \mathrm{U} / \mathrm{ml}$ penicillin, $100 \mathrm{U} / \mathrm{ml}$ streptomycin, $10 \mathrm{U} / \mathrm{ml}$ gentamycin) at $37{ }^{\circ} \mathrm{C}$ for $3 \mathrm{~h}$ and grown in a six-well plate with $1 \times 10^{6}$ cells $/ \mathrm{ml}$ in each well. The cells were incubated separately with (1) LPS (10 $\mu \mathrm{g} / \mathrm{ml}$; Sigma, St Louis, MO, USA); (2) SST-14 $(2.2 \mu \mathrm{M} / \mathrm{ml}$, Sigma); and (3) LPS $(10 \mu \mathrm{g} / \mathrm{ml})+\mathrm{SST}$ $(2.2 \mu \mathrm{M} / \mathrm{ml})$ for $24 \mathrm{~h}$. Control wells were incubated with DMEM medium only. After incubation, the supernatant of each well was collected and stored at $-70{ }^{\circ} \mathrm{C}$.

\section{Protein Extraction from Colonic Mucosa and Cells}

The mucosa was scraped from the terminal ileum of the macaques at $4{ }^{\circ} \mathrm{C}$, and the cells were snap-frozen and stored at $-80{ }^{\circ} \mathrm{C}$. The frozen samples were homogenized in a homogenization buffer ( $50 \mathrm{mM}$ Tris- $\mathrm{HCl}, \mathrm{pH} 7.2)$ containing $150 \mathrm{mM} \mathrm{NaCl}, 1 \mathrm{mM} \mathrm{Na} 3 \mathrm{VO} 4,1 \mathrm{mM}$ PMSF and a protease inhibitor cocktail (Sigma-Aldrich, St. Louis, MO) using an ultrasonic homogenizer. Each homogenate was centrifuged at $3,000 \mathrm{~g}$ for $10 \mathrm{~min}$. The supernatants were collected as total protein, and the protein concentration was measured using the Bio-Rad Protein Assay.

\section{Determination of Cytokines by Enzyme-Linked Immunosorbent Assay (ELISA)}

The expression levels of IFN- $\gamma$ in sera from the peripheral veins and portal veins, ileac mucosa protein, IECs and LPLs, lymphocytes and IECs supernatant after incubation were determined with an ELISA kit (R\&D Systems, Inc., Minneapolis, USA) according to the manufacturer's instructions. The expression levels of IL-6, IL-1 $\beta$ and TNF$\alpha$ in sera from the peripheral veins and portal veins were determined with an ELISA kit (R\&D Systems, Inc., Minneapolis, USA) according to the manufacturer's instructions.

\section{Visualization of IFN- $\gamma$, CD4, CD8 and CD57} by Immunohistochemistry

Sections of the terminal ileum were deparaffinized and microwaved for $15 \mathrm{~min}$. For nonspecific blocking, $10 \%$ goat serum was added, and the sections were incubated for $20 \mathrm{~min}$ at room temperature. The following antibodies were then added to individual sections: rabbit antihuman IFN- $\gamma$ (polyclonal antibody, 1:200, Boster Bioagent Company, Beijing, China), and mouse antihuman CD4, CD8 and CD57 (monoclonal antibody, 1:100, Zymed, CA, USA). After incubations with polyclonal antibodies for 120 min at $37{ }^{\circ} \mathrm{C}$ and overnight at $4{ }^{\circ} \mathrm{C}$, the sections were stained with a ready-to-use streptavidin-catalase immunohistochemical reagent system. The color reactions were developed with diaminobenzidine (DAB; Zhongshan Bioagent Company, Beijing, China). A semiquantitative 
immunohistochemical analysis of the raw data was performed with Image-Pro Plus 4.0 software to score integrated optical density (IOD). Each value represented the mean $\pm \mathrm{SD}$ of five visual fields in which duplicate measurements were made.

\section{Statistical Analysis}

All the quantitative data are presented as the mean \pm SD from the five animals in each group with duplicate measurements in each animal. The data were analyzed using SPSS (version 14.0; SPSS, Inc., Cary, NC, USA). The data were evaluated with an ANOVA and confirmed using a post hoc test for multiple comparisons. Significance was set at $p<0.05$.

\section{Results}

\section{Up-Regulation of IFN- $\gamma$ in IECs After IIR}

To determine the level of IFN- $\gamma$ in gut injury after IIR, we first performed immunohistochemistry and found a weak staining for IFN- $\gamma$ in the terminal ileal epithelium of the control group (Fig. 1a). After IIR, extremely strong positive staining for IFN- $\gamma$ was detected in the ileal epithelium. Positive staining for IFN- $\gamma$ was observed in both the cytoplasm and the membrane of IECs and in the lamina propria (Fig 1a). Next, to determine which group of cells leads to the excessive secretion of IFN- $\gamma$ in the intestinal epithelium, we isolated IECs and LPLs, the two main groups of cells in the gut, and analyzed the levels of IFN- $\gamma$
Fig. 1 Comparison of IFN- $\gamma$ levels in normal, IIR and SST+IIR intestines. Fifteen macaques were randomly divided into control, IIR and $S S T+I I R$ groups.

a Immunohistochemical analysis of IFN- $\gamma$ expression in the terminal ileum of the normal, IIR and SST+IIR groups ( $\times 200$ magnification). Semiquantitative analysis of these raw data was used to measure the difference among the three groups. Integrated optical density (IOD), lower panel. b Comparison of IFN- $\gamma$ levels in extracted protein of ileal tissue (tissue), intestinal epithelial cells (IEC) and lamina propria lymphocytes (LPLs) of the normal, IIR and SST+IIR groups. c Comparison of IFN- $\gamma$ levels in the supernatant of LPLs from the normal, IIR and SST+IIR groups. In b, c, the data were obtained by ELISA as $\mathrm{pg} / \mathrm{mg}$ total protein (TP) in the tissue or $\mathrm{pg} / \mathrm{ml}$ in the serum. *Compared with the control group, $P<0.05$. " Compared with the IIR group, $P<0.05$

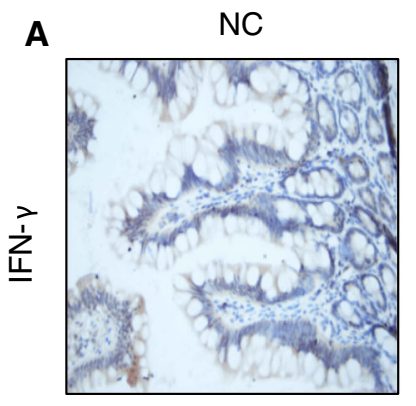

IIR
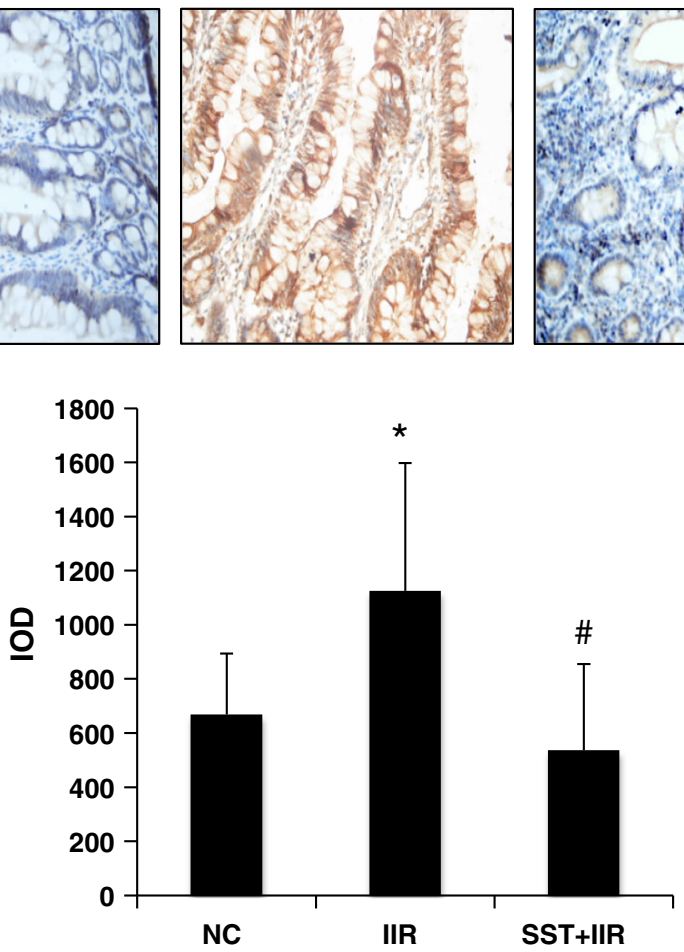
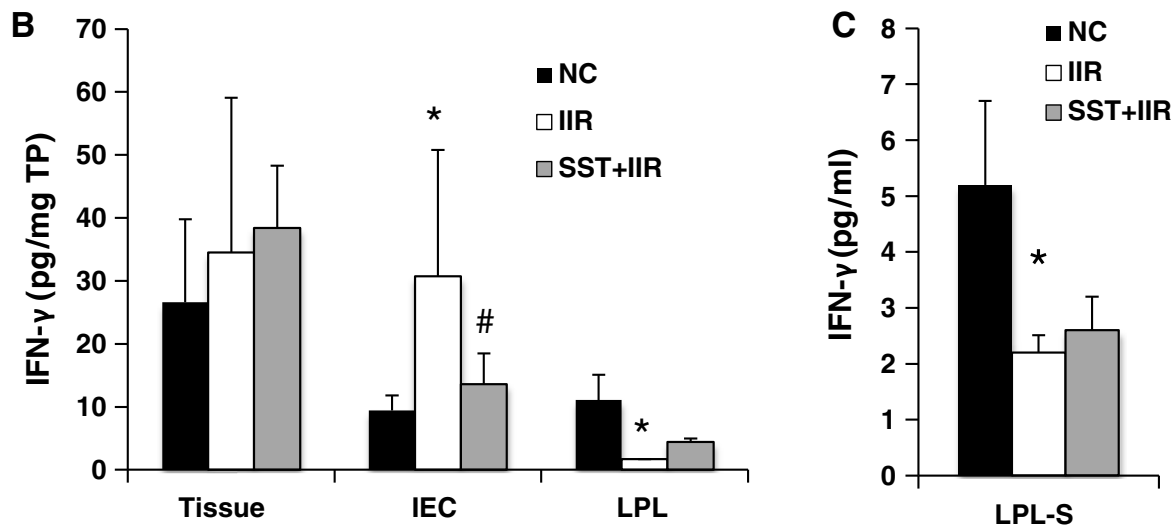
by ELISA. Interestingly, the up-regulation of IFN- $\gamma$ in IECs after IIR was confirmed by quantifying the extracted protein expression (Fig. 1b). However, the IFN- $\gamma$ level in the intestinal lymphocytes of the IIR group decreased significantly (compared to that of the controls), both in the extracted proteins of LPLs and in incubation supernatant of intact LPLs (LPL-S) after stimulation (Fig. 1c). Additionally, no significant difference in the IFN- $\gamma$ level in the total ileum between the control and IIR group was revealed. These data demonstrated that the increased expression of IFN- $\gamma$ in epithelium occurs in IECs after IIR.

Elevated Level of IFN- $\gamma$ in the Portal Vein, but Not in the Peripheral Circulation After IIR

Along with the up-regulation of IFN- $\gamma$, the levels of other proinflammatory cytokines, including IL-6, IL-1 $\beta$ and TNF- $\alpha$, increased significantly in the ileum of the IIR group (Fig. 2). This finding indicates an exacerbation of the proinflammatory status in the gut after IIR. To determine the influence of cytokines on the systemic inflammatory response, we measured the cytokine levels in both the portal vein and the peripheral circulation. All the tested cytokine levels, including IFN- $\gamma$, IL-6, IL- $1 \beta$ and TNF- $\alpha$, were increased significantly in the portal vein after IIR. The IL-6, IL-1 $\beta$ and TNF- $\alpha$ levels in the peripheral circulation were also significantly increased after IIR (Fig. 2). However, the IFN- $\gamma$ level in the peripheral circulation after IIR was not significantly different from that of the control group (Fig. 2).
Alleviation of Vital Organ Dysfunction by SST After IIR

All the experimental animals treated with IIR developed MODS, but none of the control animals did. Only one macaque (1/5) in the SST+IIR group developed MODS before being killed. There were obvious impairments of vital organs, including the small intestines, liver, lungs and kidneys in the animals treated with IIR compared with the normal control group. After the intravenous injection of SST, a significant improvement of these pathological changes was observed (Fig. 3). The alleviation of intestinal damages includes reduction in the degrees of intestinal villous atrophy, tissue edema, inflammatory cell infiltration and intestinal mucosal hemorrhage. The hepatic lobular structure became more defined with less infiltration of inflammatory cells. The tissue of the inter-alveolar space appeared much thinner, with decreased inflammatory cells infiltration and hyperemia. A reduced loss of epithelial cells from the renal tubules, with less tubular structure formation, was also observed. All these data support the protective and anti-inflammatory role of SST after IIR in macaques.

Down-Regulation of IFN- $\gamma$ in the IECs and Portal Vein, but Not in Other Immune Cells, by SST After IIR

After pretreatment with SST, immunohistochemistry showed that the IFN- $\gamma$ level in the intestinal epithelium was restored to the normal level after IIR (Fig. 1a). The
Fig. 2 Comparison of cytokine levels in portal vein and peripheral circulation of normal, IIR and SST+IIR macaques. a IFN- $\gamma$ levels were significantly increased in the portal vein (PV) but not in the peripheral circulation (PC), after IIR. In b-d, the levels of proinflammatory cytokines, including IL-6, IL- $1 \beta$ and TNF$\alpha$, were significantly increased both in the PV and in the PC. SST significantly inhibited the secretion of cytokines. The data were obtained by ELISA as pg/ $\mathrm{ml}$ in the serum. *Compared with the control group, $P<0.05$. " Compared with the IIR group, $P<0.05$
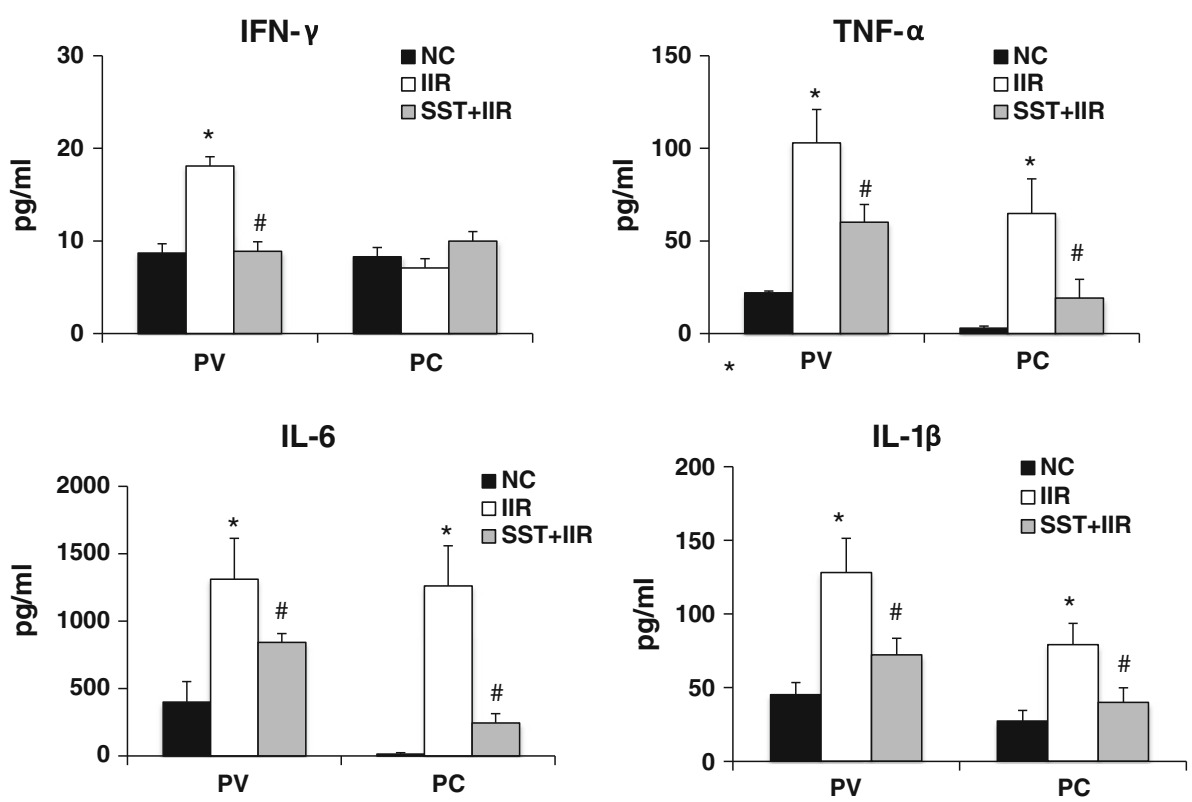

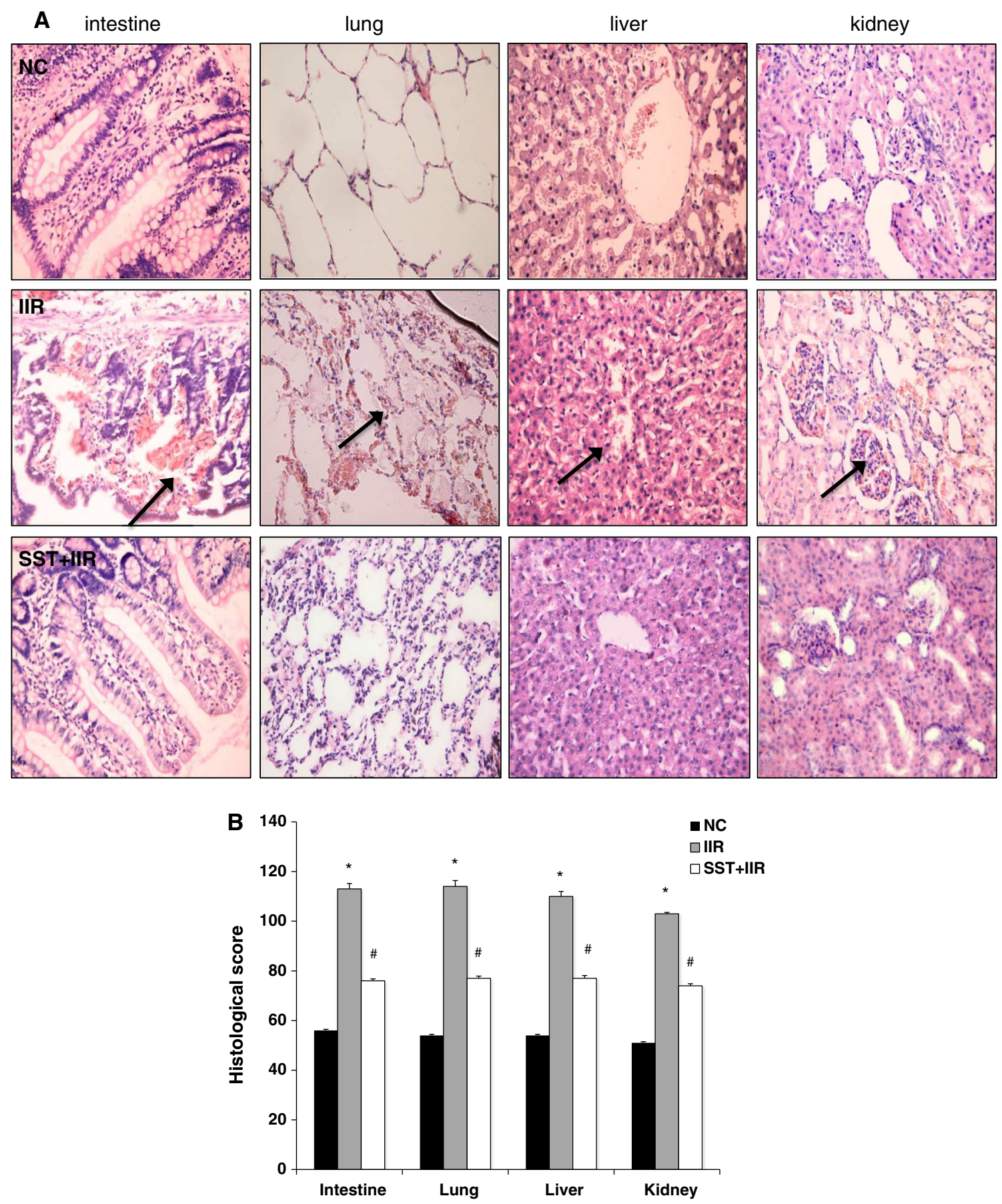

Fig. 3 Alleviating effect of SST on systemic inflammatory injury after IIR. a HE staining of vital organs in the normal, IIR and SST+IIR groups. The black arrows indicate infiltration by

inflammatory cells $(\times 200$ magnification $)$. b Disease score of vital organs in the normal, IIR and SST+IIR groups. *Compared with the control group, $P<0.05$. ${ }^{\#}$ Compared with the IIR group, $P<0.05$

cytokine levels in the IECs also decreased significantly to their normal levels, together with the IFN- $\gamma$ level in the portal vein in the SST+IIR group (Fig. 1b). However, SST did not alter the IFN- $\gamma$ down-regulation trend after IIR in the LPLs or in the culture medium from the lymphocytes after $24 \mathrm{~h}$ of incubation (Fig. 1b, c). Furthermore, no significant differences were found in the total ileum tissue or peripheral blood among the control, IIR and IIR + SST groups (Fig. 1b). These data provide evidence that SST inhibited secretion of IFN- $\gamma$ in IECs, but not in lymphocytes after IIR.

In previous data, we reported that SST receptor subtype 2 was found in intestinal epithelium of macaques [11]. To further confirm the direct role of SST on IECs, the level of 


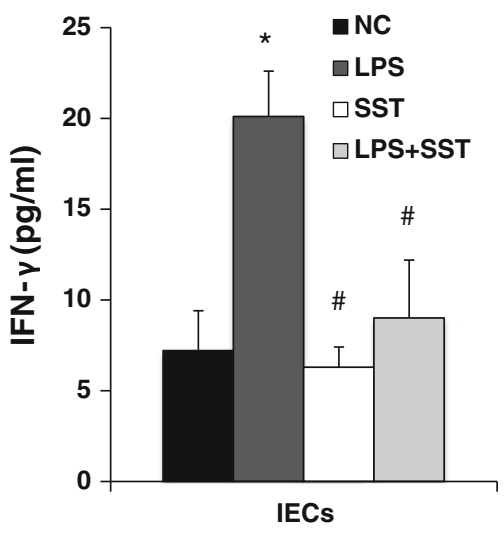

Fig. 4 Inhibition of IFN- $\gamma$ in IECs by SST in vitro isolated IECs from macaques was incubated with LPS $(10 \mu \mathrm{g} / \mathrm{ml})$, SST-14 $(2.2 \mu \mathrm{M} /$ $\mathrm{ml}$ ) and LPS + SST for $24 \mathrm{~h}$, respectively. The supernatant was collected, and the IFN- $\gamma$ level was measured by ELISA. *Compared with the normal control group, $P<0.05$. ${ }^{\#}$ Compared with the LPS group, $P<0.05$

IFN- $\gamma$ in isolated IECs was stimulated by LPS. SST significantly reduced the levels of IFN- $\gamma$ induced by LPS (Fig. 4).

To further investigate any potential influence of SST on IFN- $\gamma$ secreting by immune cells, we measured the expression of $\mathrm{CD}^{+}{ }^{+}$Th cells, $\mathrm{CD} 8^{+} \mathrm{Tc}$ cells and $\mathrm{CD} 57^{+}$natural killer cells in terminal ileal mucosa using immunohistochemistry. In a previous study, we had found that the SST level in the ileum decreased significantly after IIR and extrinsic SST reversed this change [11]. In the present study, we found that $\mathrm{CD} 4^{+}$cells were scattered throughout the intestinal epithelium and lamina propria, but the number of these cells was reduced significantly by the decreased level of SST after IIR. Extrinsic SST did not change the expression of CD4 (Fig. 5a, b). Normal CD8 ${ }^{+}$cells were scattered throughout the intestinal epithelium (but not in lamina propria) and disappeared after IIR. Prophylactic SST induced the expression of $\mathrm{CD}^{+}$and restored it to the normal level. Compared to the IIR group, the trends of $\mathrm{CD}^{+}$expression was opposite to that of IFN- $\gamma$ in SST+IIR group (Fig. 5a, b). $\mathrm{CD} 57^{+}$cells were only scattered in the lamina propria of epithelium in normal condition and increased significantly after IIR. SST significantly increased the expression of $\mathrm{CD} 57^{+}$, which indicates the irrelevance of the change in $\mathrm{CD} 57^{+}$to that of IFN- $\gamma$ and SST in the ileum (Fig. 5a, b). All these data provide evidence that the changes in the other immune cells were not related to IFN- $\gamma$ secretion in the IIR model (Fig. 6).

\section{Discussion}

Intestinal epithelial cells play a key role in intestinal mucosal immunity. In the past, more attention has been paid to the passive barrier function, which protects the underlying tissues and nonspecific defenses secreted by IECs, such as mucus, lysozyme and the transport of secretory immunoglobulins. Now, there is a growing appreciation that IECs release multiple cytokines, chemokines and inflammatory mediators in response to antigenic stimulus [23, 24]. After IIR-induced gut injury, numerous bacteria invade IECs, which leads to bacterial translocation, the main pathogenesis of MODS [25, 26]. However, little is known about the role of IECs in the secretion of cytokines after IIR in humans. To our knowledge, this is the first report to demonstrate that ileal epithelial cells are an important producer of IFN- $\gamma$ in primates. Interestingly, as SST significantly alleviated the gut injury in the SST+IIR group, the IFN- $\gamma$ derived from IECs decreased significantly. This finding suggests that IECs-derived IFN$\gamma$ plays a crucial role in the development of MODS. It is worth noting that although lymphocytes, $\mathrm{CD} 4^{+} \mathrm{T}$ cells, $\mathrm{CD} 8^{+} \mathrm{T}$ cells and $\mathrm{CD}^{+} 7^{+}$natural killer cells have been reported to be the main sources of IFN- $\gamma$ in intestinal inflammation [12], a higher level of IFN- $\gamma$ secretion was not observed in those cells in our IIR model.

Another important component of the intestinal mucosal immune system is the mast cells, which derive from pluripotent precursor cells in the bone marrow or hematopoietic tissue. After entering the intestinal mucosa, mast cells mature under the influence of local microenvironmental conditions, and they localize preferentially next to vascular nerve terminals in the lamina propria [6]. Interestingly, receptors for IFN- $\gamma$ have been detected on both mouse [27] and human [19] mast cells. In addition, the stimulation of various mast cell populations with IFN- $\gamma$ in both vitro and in vivo models has been reported to modulate the degranulation and activation of mast cells [19, 28]. Recently, it was reported that the mast cell expression of IFN- $\gamma \mathrm{R}$ was required for the optimal development of many features, including inflammation, local remodeling and the markedly increased expression of several cytokines, chemokines, and markers of an alternatively activated macrophage response [18]. Here, we showed an inverse relationship between IFN- $\gamma$ and SST in the intestinal epithelium. Based on our previous and present works, we hypothesize that SST modulates IFN- $\gamma$ in the normal intestinal mucosa, but mast cells are not activated. After IIR, along with the reduction in the SST level, the IFN- $\gamma$ derived from IECs was significantly increased. Under such microenvironmental conditions, mast cells were reactivated, which resulted in an excessive natural immune response. The prophylactic supplementation of SST indirectly prevented intestinal mucosal mast cell degranulation by reducing the secretion of IFN- $\gamma$ by IECs, thus preventing multiple organ dysfunction syndromes. Most importantly, using the IIR model, we have shown that SST 
A

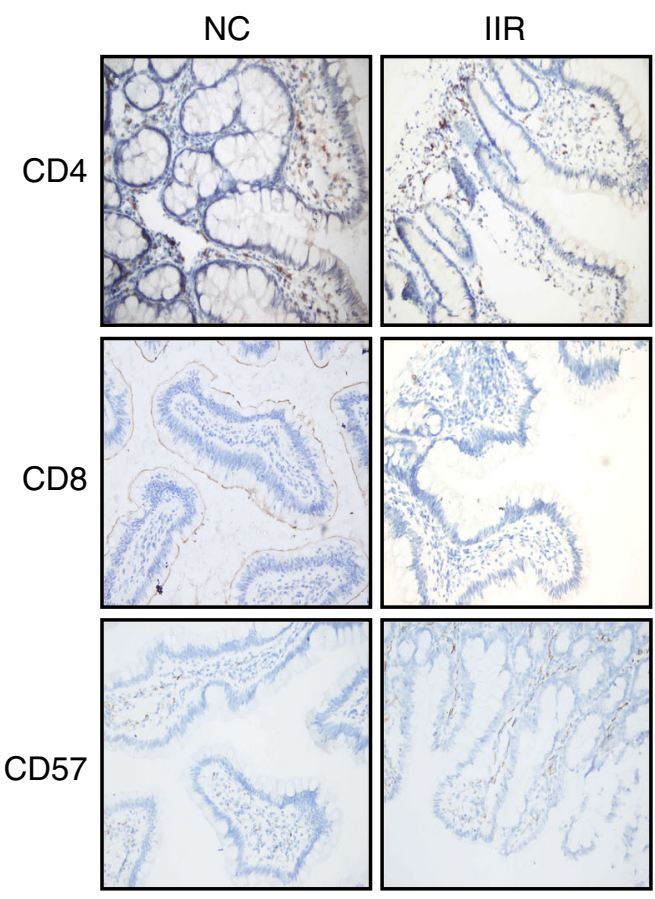

SST+IIR
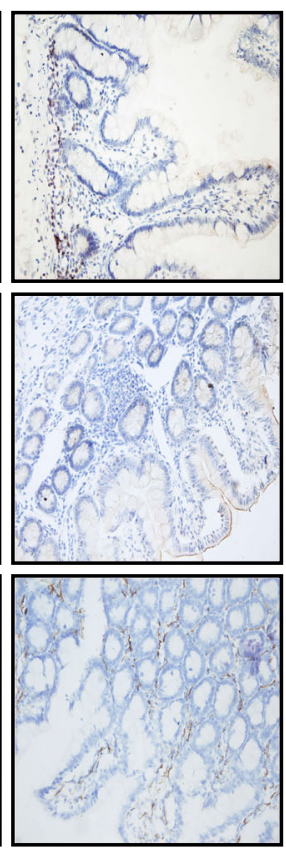

\section{B}
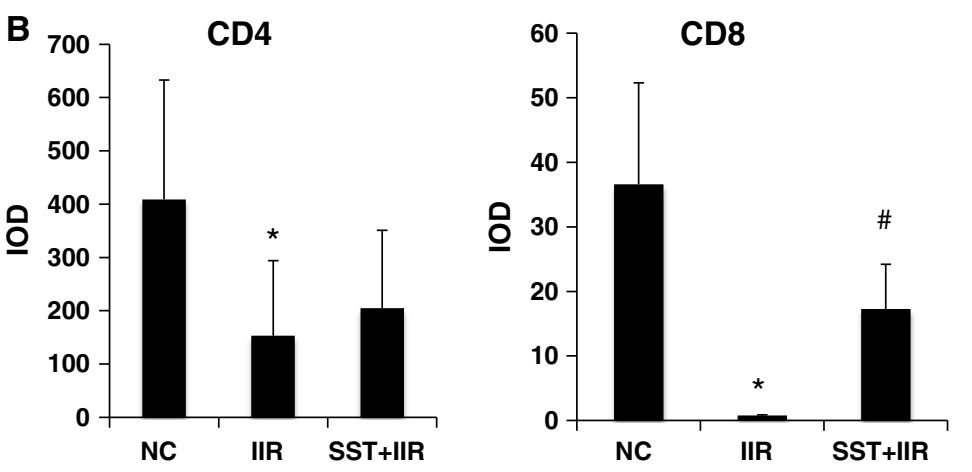

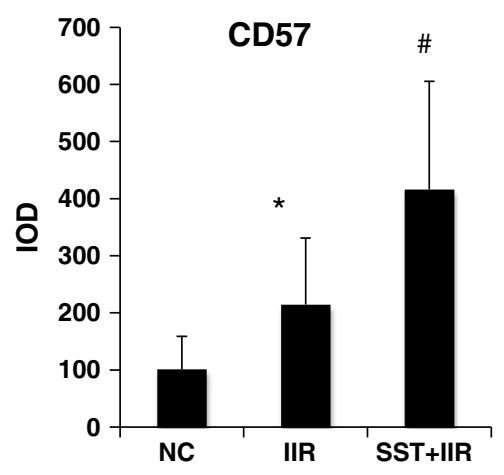

Fig. 5 Expression of CD4, CD8, CD57 in normal, IIR and SST+IIR intestines. a Immunohistochemical staining of CD4, CD8 and CD57 in normal, IIR and SST+IIR intestines. b Semiquantitative analysis of these raw data. The integrated optical density (IOD) was used to measure the difference. *Compared with the control group, $P<0.05$. ${ }^{\#}$ Compared with the IIR group, $P<0.05$

protection in the systemic inflammatory response. Then, the remaining IFN- $\gamma$ that is not catabolized by the liver flows into the pulmonary circulation, successively via the hepatic vein, inferior vena cava, right atrium, and right ventricle. Interestingly, the human lung contains abundant mast cells that exhibit similar subtypes to those in the intestine [for instance, more than $90 \%$ are $\mathrm{MC} \gamma$ subtype (i.e., only tryptase containing)]. Therefore, IFN- $\gamma$ may easily target, activate mast cells in the lung and then cause the acute lung injury or ARDS [30]. This may partly explain why the lung is the first and most common organ to be injured in MODS. In the other words, the lung should be recognized as the second gate of physiological protection organ in the systemic inflammatory response. Due to its experience in the metabolism and consumption of these two organs, the liver and lung, IFN- $\gamma$ rarely enters the 


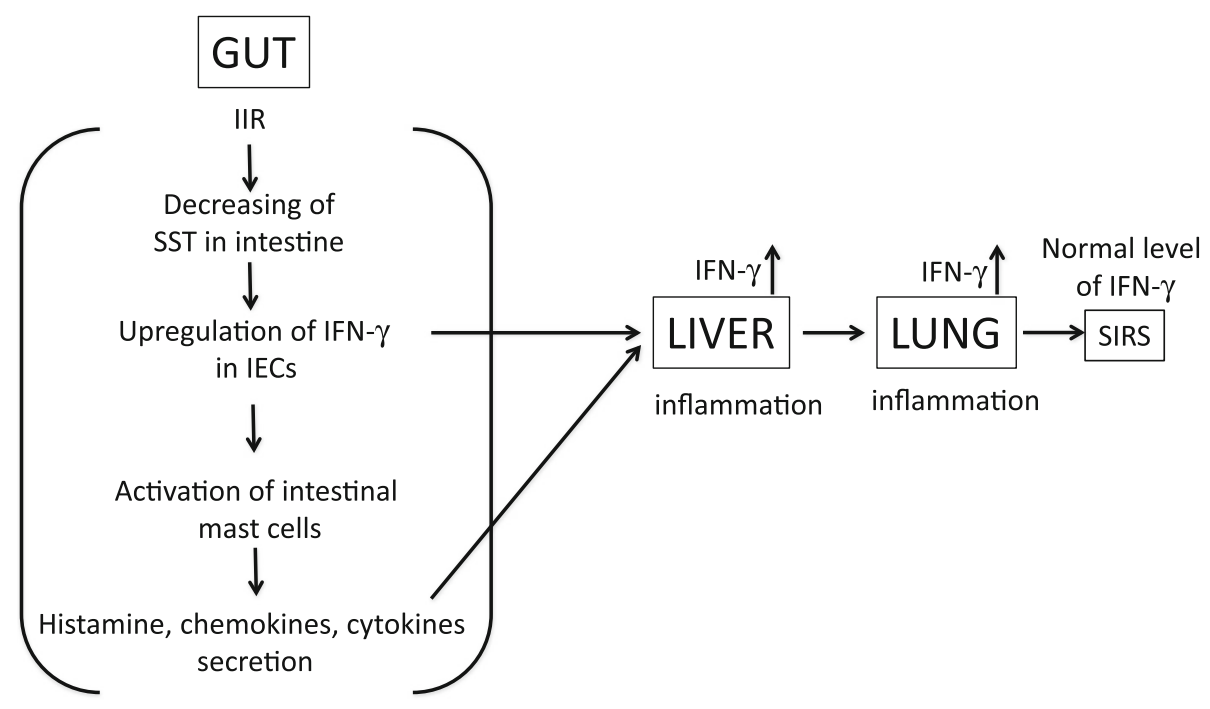

Fig. 6 Illustration of the interaction of IFN- $\gamma$, mast cells and SST in the IIR model. Intrinsic SST levels are significantly decreased under IIR conditions. Low levels of SST improve the secretion of IFN- $\gamma$ from intestinal epithelial cells (IECs), followed by activation of intestinal mast cells and excessive natural immune response. These cytokines and chemokines derived from the intestine promote

peripheral circulation. Therefore, pathological injuries to other organs, such as the kidney, may not be associated with IFN- $\gamma$.

In conclusion, we demonstrated that the ileal epithelial cells were the main source of IFN- $\gamma$ production in the intestinal mucosa after IIR. Moreover, this function was negatively regulated by SST, leading to an alleviation of the systemic inflammatory response. These results, together with the finding concerning IFN- $\gamma$, mast cells and SST, may not only enhance the current understanding of intestinal mucosal innate immunity but also provide new concept or opportunity for the prevention and treatment of MODS.

Acknowledgments This study is supported by Key Grant 30330270 of Natural Science Fund of China.

Conflict of interest The authors declares that they do not have conflict of interest.

Open Access This article is distributed under the terms of the Creative Commons Attribution Noncommercial License which permits any noncommercial use, distribution, and reproduction in any medium, provided the original author(s) and the source are credited.

\section{References}

1. American gastroenterological association medical position statement: guidelines on intestinal ischemia. Gastroenterology. 2000;118:951-953.

2. Puleo F, Arvanitakis M, Van Gossum A, Preiser JC. Gut failure in the ICU. Semin Respir Crit Care Med. 2011;32:626-638. systemic inflammatory response. IFN- $\gamma$ plays a crucial inflammatory role in the liver and heart but not in the peripheral circulation. Overall, supplementation with SST indirectly results in inhibition of IECs-derived IFN- $\gamma$ secretion, activation of mast cells and systemic inflammatory response syndrome (SIRS) in vital organs

3. Rotstein OD. Pathogenesis of multiple organ dysfunction syndrome: gut origin, protection, and decontamination. Surg Infect. 2000;1:217-223; discussion 223-225.

4. Clark JA, Coopersmith CM. Intestinal crosstalk: a new paradigm for understanding the gut as the "motor" of critical illness. Shock. 2007;28:384-393.

5. Theoharides TC, Alysandratos KD, Angelidou A, et al. Mast cells and inflammation. Biochim Biophys Acta. 2012;1822:21-33.

6. Ramsay DB, Stephen S, Borum M, Voltaggio L, Doman DB. Mast cells in gastrointestinal disease. Gastroenterol Hepatol. 2010;6:772-777.

7. Huber M. Microfilaments make mast cells migrate (rather than degranulate). Eur J Immunol. 2013;43:1698-1701.

8. Tang CW, Lan C, Liu R. Increased activity of the intestinal mucosal mast cells in rats with multiple organ failure. Chin J Dig Dis. 2004;5:81-86.

9. Tang C, Lan C, Wang C, Liu R. Amelioration of the development of multiple organ dysfunction syndrome by somatostatin via suppression of intestinal mucosal mast cells. Shock. 2005;23:470-475.

10. Saavedra Y, Vergara P. Somatostatin inhibits intestinal mucosal mast cell degranulation in normal conditions and during mast cell hyperplasia. Regul Pept. 2003;111:67-75.

11. Wu H, Liu L, Tan Q, et al. Somatostatin limits intestinal ischemia-reperfusion injury in macaques via suppression of TLR4-NFkappaB cytokine pathway. $J$ Gastrointest Surg. 2009;13:983-993.

12. Schoenborn JR, Wilson CB. Regulation of interferon-gamma during innate and adaptive immune responses. Adv Immunol. 2007;96:41-101.

13. Ito R, Shin-Ya M, Kishida T, et al. Interferon-gamma is causatively involved in experimental inflammatory bowel disease in mice. Clin Exp Immunol. 2006;146:330-338.

14. Nava P, Koch S, Laukoetter MG, et al. Interferon-gamma regulates intestinal epithelial homeostasis through converging betacatenin signaling pathways. Immunity. 2010;32:392-402. 
15. Schoeler D, Grutzkau A, Henz BM, Kuchler J, Kruger-Krasagakis S. Interleukin-6 enhances whereas tumor necrosis factor alpha and interferons inhibit integrin expression and adhesion of human mast cells to extracellular matrix proteins. J Invest Dermatol. 2003;120:795-801.

16. Eastmond NC, Banks EM, Coleman JW. Nitric oxide inhibits IgE-mediated degranulation of mast cells and is the principal intermediate in IFN-gamma-induced suppression of exocytosis. $J$ Immunol. 1997;159:1444-1450.

17. Wills FL, Gilchrist M, Befus AD. Interferon-gamma regulates the interaction of RBL-2H3 cells with fibronectin through production of nitric oxide. Immunology. 1999;97:481-489.

18. Yu M, Eckart MR, Morgan AA, et al. Identification of an IFNgamma/mast cell axis in a mouse model of chronic asthma. J Clin Investig. 2011;121:3133-3143.

19. Yanagida M, Fukamachi $\mathrm{H}$, Takei $\mathrm{M}$, et al. Interferon-gamma promotes the survival and Fc epsilon RI-mediated histamine release in cultured human mast cells. Immunology. 1996;89:547-552.

20. Poon RT, Yeung C, Lo CM, Yuen WK, Liu CL, Fan ST. Prophylactic effect of somatostatin on post-ERCP pancreatitis: a randomized controlled trial. Gastrointest Endosc. 1999;49:593-598.

21. Weigmann B, Tubbe I, Seidel D, Nicolaev A, Becker C, Neurath MF. Isolation and subsequent analysis of murine lamina propria mononuclear cells from colonic tissue. Nat Protoc. 2007;2:2307-2311.

22. Lefrançois L, Lycke N. Isolation of mouse small intestinal intraepithelial lymphocytes, Peyer's patch, and lamina propria cells. Curr Protoc Immunol. 2001;Chapter 3:Unit 3.19. doi:10. 1002/0471142735.im0319s17.

23. Gopal R, Birdsell D, Monroy FP. Regulation of chemokine responses in intestinal epithelial cells by stress and Toxoplasma gondii infection. Parasite Immunol. 2011;33:12-24.

24. Stadnyk AW. Intestinal epithelial cells as a source of inflammatory cytokines and chemokines. Can $J$ Gastroenterol. 2002;16:241-246.

25. Louis K, Netea MG, Carrer DP, et al. Bacterial translocation in an experimental model of multiple organ dysfunctions. J Surg Res. 2013;183:686-694.

26. MacFie J. Current status of bacterial translocation as a cause of surgical sepsis. Br Med Bull. 2004;71:1-11.

27. Nafziger J, Arock M, Guillosson JJ, Wietzerbin J. Specific highaffinity receptors for interferon-gamma on mouse bone marrowderived mast cells: inhibitory effect of interferon-gamma on mast cell precursors. Eur J Immunol. 1990;20:113-117.

28. Bissonnette EY, Chin B, Befus AD. Interferons differentially regulate histamine and TNF-alpha in rat intestinal mucosal mast cells. Immunology. 1995;86:12-17.

29. Grootjans J, Lenaerts K, Derikx JP, et al. Human intestinal ischemia-reperfusion-induced inflammation characterized: experiences from a new translational model. Am $J$ Pathol. 2010;176:2283-2291.

30. Huang P, Liu D, Gan X, et al. Mast cells activation contribute to small intestinal ischemia reperfusion induced acute lung injury in rats. Injury. 2012;43:1250-1256. 